\title{
The ergonomic evaluation of a virtual learning environment usability
}

\author{
Aliana Pereira Simões ${ }^{\mathrm{a},{ }^{*}}$ and Anamaria de Moraes ${ }^{\mathrm{a}}$ \\ ${ }^{a}$ Department of Art and Design, then Pontificia Universidade Católica, Rua Marquês São Vicente n²25- Gávea, \\ Rio de Janeiro, Brazil
}

\begin{abstract}
The article presents the processes and the results of the application of some ergonomic techniques, used to evaluate the usability of the virtual learning environment adopted by the Distance Education Center of the Federal Institute of Espírito Santo - Brazil.
\end{abstract}

Keywords: ergonomic, usability, design, e-learning

\section{Introduction}

The ways of teaching and learning represented in the virtual learning environment are still in stage of development. A lot must be done so the method of distance courses planning includes in its process, disciplines that allow the development of effective, efficient and satisfactory interaction tools for the users (students, monitors, etc.).

The ergonomics is one of these disciplines. One of its functions in the evolutive process of educational software is to contribute with methods and techniques that allow the knowledgement of the relation between the user and the learning tools.

The objective of this study was to make the ergonomic evaluation of the usability of a virtual learning environment to demonstrate that the lack of knowledgement of the benefits and the no application of the usability and ergodesign principles favor the construction of ergonomically inadequate software programs in DE, with low quality of use and unsatisfactory for the students.

The virtual learning environment adopted by CEAD/IFES (Distance Education Center of the Federal Institute of Espírito Santo - Brazil) was the objective of this study; this environment uses the software Moodle to interact with the students.

This center was chosen for this survey for two reasons: the first one is that the institution identified that its students have great interaction difficulties with the learning environment. And the second reason was that this CEAD is part of the Open University of Brazil (UAB), a program of the Brazilian government that aims quality undergraduate education to graduate teachers. Therefore, it is possible that the problems found in this study and the suggested ergonomic recommendation might be used in other UAB centers, then the great majority of these centers adopt the software Moodle to present their virtual learning environments.

\section{Metodology}

For making the evaluation, it was defined the following methods and techniques: application of SUS questionnaire (System Usability Scale) - to measure the user level of satisfaction; for the evaluation of the interface design, the method of Heuristic Evaluation was selected ([6]Preece et al, 2005) and to evaluate the system usability by the user, the application of the Cooperative Evaluation (Monk et.al, 1993).

\subsection{SUS Questionnaire}

The first technique used was the SUS (System Usability Scale) Questionnaire. This questionnaire was developed by Digital Equipment CO Ltd., to evaluate the usability of systems and products developed in a company. It's a simple and quick applica-

*E-mail: aliana@aliana.com.br 
tion questionnaire which demonstrates a general and subjective view of product usability and it also evaluates the user satisfaction regarding the product. It is composed by 10 questions that evaluate the following items:

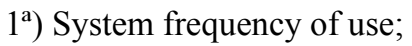

$2^{\mathrm{a}}$ ) System complexity;

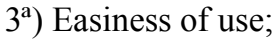

$4^{\text {a }) ~ A s s i s t a n c e ~ t o ~ u s e ~ t h e ~ s y s t e m ; ~}$

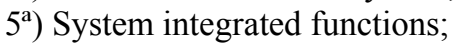

$6^{\text {a }) ~ S y s t e m ~ i n c o n s i s t e n c e ; ~}$

$7^{\text {a) }}$ Quick learning;

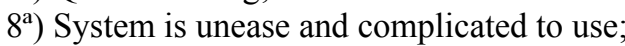

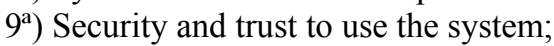

$10^{\mathrm{a}}$ ) Learning of other information to use the system

Besides these questions, the questionnaire has an open field so the user can make any comments about the system.

The questionnaire was answered by 59 users, students from the first semester of the Information Technology Degree Course and people who are familiar to this tool for four months.

\subsection{Cooperative application}

According to [3]Monk et.al (1993), the Cooperative evaluation is a method that identifies the points on the interface which make the user interaction more difficult. It is a co-operation technique that involves users and evaluators. It's easy to apply, as the user together with the evaluator, informally verbalizes the problems found on the interface. It is very efficient to find recurring and high severity problems in the real context of use.

Based on SUS results, it was decided to define a group of users that don't know the tool to make a Cooperative evaluation. Then, the questionnaire proved that the students had initial difficulty in learning the environment, but the level of difficulty decreased with the constant use of it.

Other pre-requirement for the selection of users was their age. The users were over 30 years old, CEAD IFES/ES students' average age. Eleven users were evaluated in total.

For the evaluation, it wasn't used a prototype, but the learning environment, which is available to all IFES/ES users. Before the evaluation, the aim of the survey and the evaluation method were explained to the user. After the explanation, the user received a paper with a "thank you for your participation" text and the description of the tasks steps.

The users selected for the evaluation performed some typical students' tasks on the environment and then gave their opinion about the difficulties of use found in the interaction process with the tool. The tasks were defined after the application of a pre-test performed in a group of five users with the same profile of the final user.

A recorder, paper and pen were used to register the evaluation. After the evaluation, the users had the liberty to opine about the environment usability and interface. Some users recommended solutions to improve the environment usability and interface. It wasn't possible to gather all the investigated users to review the problems and create solutions.

\subsection{Heuristic evaluation}

The last method applied was the Heuristic evaluation. According to [6]Preece et.al (2005), the terminology "heuristic evaluation" was introduced by Nielsen and Rolf Molich during the 90's. It consists in an inspection method of usability, performed by specialists of the usability area that uses a group of heuristic principles as a reference to evaluate if the elements of a particular interface are according to the selected principles.

It's a simple, efficient, low cost method and can be applied in any stage of the project development. For the application of this method, it is necessary the selection of 3 to 5 specialists who must exam a chosen interface with the aim of looking for problems that are in disagreement with the principles for a good interface project.

For this evaluation, it was defined four specialists (two specialists in Ergonomics in HIC, a master in Computer Science and a doctor in Design). These specialists received a check list composes by 117 items that evaluates: the system visibility; the parity between the system and the real world; user control and liberty; flexibility and efficiency of use, minimalist aesthetic and design; Consistence and standards; errors prevention; help and documentation; diagnosing and recovering error actions; navigation, disorientation and cognitive overload. These evaluation points were defined from the recommendations elaborated by $[5,6,7,1]$ Nielsen, Bastien and Scapin, Shneider-man (apud Santos 2000) and Preece et al. (2005), and also consulting authors such as Padovani (1998), Barnum (2002). 
Table1

\begin{tabular}{|c|c|c|}
\hline \multicolumn{3}{|c|}{ Comparison of the results. } \\
\hline $\begin{array}{l}\text { SUS } \\
\text { ( Items found bellow the } \\
\text { average ) }\end{array}$ & Cooperative Evaluation & Heuristic Evaluation \\
\hline $\begin{array}{l}\text { The learning of other } \\
\text { information to use the } \\
\text { system }\end{array}$ & $\begin{array}{l}\text { - Some users from the evaluation } \\
\text { compared some software's functions } \\
\text { to functions of another tool already } \\
\text { used; } \\
\text { - They highlighted that it is im- } \\
\text { portant to have minimum knowledge } \\
\text { in internet to use the software. }\end{array}$ & \multirow{5}{*}{$\begin{array}{l}\text { - There aren't instructions for navigation; } \\
\text { - The instructions aren't on the same place and visible on the screen; } \\
\text { - The colors used don't help in the attention direction; } \\
\text { - The screen doesn't highlight the important information to the user; } \\
\text { - The menus aren't used, named and placed consistently } \\
\text { - There is no identification on the pages; } \\
\text { - The system doesn't allow the marking of pages that interest the user; } \\
\text { - The system uses difficult interpretation abbreviations. } \\
\text { - All the accesses aren't presented on the screen; } \\
\text { - System terminology isn't familiar } \\
\text { - The page identification elements aren't readable; } \\
\text { - The system uses difficult interpretation abbreviations; } \\
\text { - Messages aren't that specific, brief, understandable and objective; } \\
\text { - The error messages aren't effective; } \\
\text { - Link "Help" isn't highlighted. } \\
\text { - The terminologies aren't consistent in the text and in the instructions; } \\
\text { - Lack of standardization of the links and icon colors; } \\
\text { - There isn't a basic diagram for the screens. } \\
\text { - The screen doesn't highlight the important information to the users; } \\
\text { - It doesn't exist a progressive level of details between the pages; } \\
\text { - The groups of differentiated information don't have a consistent visual } \\
\text { difference; } \\
\text { - The icons don't highlight themselves on the screen; } \\
\text { - The sections, chapters aren't organized according to the users' aims; } \\
\text { - System doesn't allow retro navigation; } \\
\text { - System causes damage to the work flow when the user cancels an } \\
\text { - System doesn't present effective error messages; } \\
\text { - It doesn't exist confirmation for commands with drastic consequences; } \\
\text { - The system doesn't use aid for navigation and doesn't use warning } \\
\text { resources when they are necessary. }\end{array}$} \\
\hline The system complexity & $\begin{array}{l}\text { •It was confirmed through the } \\
\text { system navigation and the users got } \\
\text { confused with the amount of infor- } \\
\text { mation. Some information had no } \\
\text { sense to the user, such as: "HTML } \\
\text { format" and "JavaScript use". }\end{array}$ & \\
\hline System inconsistence & $\begin{array}{l}\text { - The system doesn't follow a } \\
\text { standard on the initial screens; } \\
\text { • Error and warning messages } \\
\text { aren't standardized. }\end{array}$ & \\
\hline Quick Learning & $\begin{array}{l}\text { - The users highlighted that it is } \\
\text { necessary a training to learn how to } \\
\text { use the system; } \\
\text { - A task (get back to the main } \\
\text { screen and select a course) was } \\
\text { asked twice to the user. In the } \\
\text { second time, the users had difficulty } \\
\text { in memorizing to do it; } \\
\text { - Lack of aid resources. }\end{array}$ & \\
\hline $\begin{array}{l}\text { Security and Reliability to } \\
\text { use the system }\end{array}$ & $\begin{array}{l}\text { - Some users got frustrated and } \\
\text { insecure when interacting with the } \\
\text { system. }\end{array}$ & \\
\hline
\end{tabular}

The researcher met, separately, each specialist and each checklist item was approached together with the visualization of the learning virtual environment. The average time of each evaluation was of two hours. After gathering all the raised problems, the researcher sent them to the specialists to grade them separately. It wasn't possible to gather all the specialists due to the time availability and access difficulty.

\section{Results}

The obtained results pointed that this environment presents severe usability problems. The SUS questionnaire highlighted the following problems: the environment is too complex, inconsistent, and difficult to learn; the users don't feel safe to use the environment and it is necessary the learning of other information to use the environment.

The Cooperative evaluation confirmed the results found by SUS and highlighted other relevant data that justify the users' dissatisfaction with the environment. These data point that the environment presents severe problems of navigation and functionality.

The heuristic evaluation results also confirmed the results found by SUS and Cooperative evaluation. Eighty four percent of the problems were scored as a catastrophe and bigger usability problem by the specialists.

The results of the Cooperative evaluation were compared with the questionnaire results and the heuristic evaluation (table 1). The aims were to identify if the usability problems in the evaluation with the user correspond to the problems found by specialists and if these specialists point new problems that weren't detected by the user.

The heuristic evaluation brought in its results the highlight for the environment design and pointed some items that weren't explained in the Cooperative evaluation and in the SUS questionnaire. These items can help in the interaction process between the user and the environment. Among them, it's possible to highlight:

- The environment can't support new and inexperienced users;

- The use of colors to indicate that the action was performed;

- The use of visual maps to show the relation between the knowledgements;

- The use of a question/ search tool;

So, as in the Cooperative evaluation, the heuristic evaluation detected that the environment presents several navigation and information architecture problems. 
The Cooperative evaluation was fundamental to detect the correct position of the problems. The heuristic evaluation is a great method; almost all the data found in this method were also found in the Cooperative evaluation, but the evaluation with the user brought more significant data for the environment interface reformulation.

\section{Final recommendations}

It follows bellow, a resume of the suggested recommendations to improve the environment design and usability:

- Identifying the institution's name in all the environment screens;

- Standardizing all the software screens and graphic elements;

- Making the retro navigation easier, inserting on all pages a link that leads to the main page;

- Valorizing the blank spaces and use the symmetry and well alignment in diagramming the screen contents;

- No use of abbreviations, using simple and familiar language to the user;

- Highlighting the personalized page for the student;

- Decreasing the size of the scrollbar and improving the icon that demonstrates the function of decreasing the amount of contents on the screen;

- Highlighting the buttons which give access to the main page and add readable buttons to the retro navigation;

- Adding an effective searching system that is present on all the screens;

- Highlighting the compulsory fields with symbols and messages of understandable texts;

- Decreasing the highlight for information that isn't part of the student's reality, e.g.: "version without frameset" or "HTML". In case of being important to the student having the knowledge of this information, the system must present an informative text for each one.

- Differentiating the message that indicates the system processing;

- Not loading a heavy page for the error, confirmation and warning messages;

- Adding an aid resource on all screens;

- A warning resource must be presented to the user when it's necessary. This resource must be composed by brief and objective messages;
- Increasing the spaces between the "delete", "edit" and "answer" buttons;

- Adding a button to "exit" the system;

- Increasing the text formatting and presenting to the user an option to control the text size and contrast;

- Highlighting the "Activities" box for the student;

- Using understandable warning and error messages for the user;

- Using more color contrast in the buttons;

- Continuing the use of breadcrumb;

- Improving the alignment in the form fields;

- Presenting the user a more objective way to "delete" and "edit" a registered text;

- Identifying the tasks performed by the students;

- Improving the resource of online communication;

- Presenting a new way of navigation. In case it's not possible, the system must present visible and standardized instructions to help in the navigation; the navigation menu must be efficient with understandable levels of navigation for the user and organized hierarchically;

- Consistently positioning the navigation menus. The system must offer more than one way to access the information. It is suggested the inclusion of an horizontal menu besides the left side menu

- Presenting visual maps;

- For making the accessibility easier, the system must use the resources of the navigation keyboard;

- Presenting subtitles to help the user to read long and not obvious contents;

- Supporting new and experienced users, presenting different dialogues for different users;

- Guaranteeing that the system doesn't cause damage to the work flow;

- Presenting interactive tutorials in the system;

\section{Discussions}

The SUS questionnaire is an objective and efficient tool to have a notion about the usability and users' satisfaction. About the results found in the closed questions, the higher average corresponds to the frequency of use of the system $(71,61)$. This number can be related to the obligation of the student to interact with the system several times a week to perform the activities. Some students commented, orally, that in the beginning they had difficulties with the system, but after the training section given by CEAD/IFES and the constant use, the tool was more 
intuitive and satisfactory. Therefore, the frequency of use can interfere in the system usability and user's satisfaction.

With the obtained results, it's been already possible to make some recommendations that will help the interface improvement. These results also contributed to the survey's course. An example of this course is that in the beginning of the survey, it was decided to select the CEAD IFES/ES students to participate of the Cooperative Evaluation process, but because of the obtained results - mostly by the fact of the students already consider the tool easy due to its constant use - the next step was to select the users who didn't know the tool that validates the problems found and discover if the tool has other problems of use that make its quick learning more difficult.

Even having the ergonomic and the design as a focus, the questionnaire application showed some pedagogic problems: the delay in the return of the distance monitor, the environment must have more tutorials, the tasks could be sent by e-mail and lack of use of the system's video-conference resource. These problems were told to the instructional designer and the CEAD/IFES pedagogic team. Before this fact, it was concluded that this ergonomic technique can also help in the pedagogic planning improvement.

This questionnaire application could be done by internet, but the researcher's presence incentivized the users to think better about their difficulties of interaction with the software. Students and coordinators from the units with in attendance classes praised the support given to the survey and CEAD/IFES care to improve the learning environment.

The Cooperative evaluation method was very well accepted by the users. They felt really comfortable to criticize and to suggest improvements to the environment. The pre-test was fundamental to decide the tasks titles and the order of each one.

[3]Monk et al.(1993) were correct to describe that the Cooperative evaluation must be applied to five users, because a bigger quantity of users can lead to repetition of problems. This survey was conducted with eleven users and the majority of the problems found were identified by all of them.

The results found confirmed the bellow the average issues of the SUS questionnaire (first technique used to evaluate the satisfaction and the software usability) that were: the learning of other information to use the system; the system complexity; system inconsistence; quick learning; security and trust to use the system.
There weren't complaints of pedagogic learning problems during the Cooperative evaluation; maybe this fact is due to the choice of tasks, because their aim was the use of the environment without incentive of learning any pedagogic contents.

The elaboration of a checklist made the heuristic evaluation easier, and then the specialists used the checklist as a support tool for the analysis. The difference of the specialists' academic formatting might have influenced in the result because the master in computer science specialist focused more in the system security, speed and functionality analysis. The doctor in design specialist highlighted, with more emphasis, the bad use of the interface's graphic elements and the USIHC specialist focused on the usability problems of the environment.

The CEAD/IFES learning environment has the software Moodle as a basis. The interface design of this environment is customized by CEAD and its graphic elements and icons weren't criticized by the majority of the users. There were strong critics about the navigation and this software's functionality. The navigation and the functionalities are standardized by the software Moodle and can be found in any learning environments that use this platform. Some recommendations presented are sent to CEAD/IFES-ES, but can be applied in other learning environments that use Moodle.

\section{References:}

[1] Barnum, C. M. Usability Testing and Research. United States. Pearson Education, 2002.

[2] Jordan, P. W. Designing Pleasurable Products: An introduction to the new human factors. United States of America, New York: Taylor\&Francis, 2000.

[3] Monk, A.; Wright, P.; Haber, J.; Davenport, L. Improving your human-computer interface: a practical technique. Prentice Hall International (UK) Ltd, 1993.

[4] Moraes, A.; Amado, G. (Org.). Coletânea de Palestras de convidados internacionais e nacionais: Ergodesign e USIHC. Rio de Janeiro:FAPERJ, iUsEr, 2004.

[5] Padovani, S. Avaliação ergonômica de sistemas de navegação em hipertextos fechados. Masters Dissertation, PUC-Rio, 1998.

[6] Preece, J. et al. Design de interação homemcomputador. Porto Alegre: Bookman, 2005.

[7] Santos, R. L. G. Ergonomização da interação humanocomputador: abordagem heurística para avaliação de usabilidade de interfaces. Masters Dissertation, PUCRio, 2000. 